Association for Information Systems AIS Electronic Library (AISeL)

DIGIT 2004 Proceedings

Diffusion Interest Group In Information Technology

2004

\title{
Central and Peripheral Routes to Sustained Technology Usage
}

Corey Angst

University of Maryland, cangst@rhsmith.umd.edu

Ritu Agarwal

University of Maryland, ragarwal@rhsmith.umd.edu

Follow this and additional works at: http://aisel.aisnet.org/digit2004

\section{Recommended Citation}

Angst, Corey and Agarwal, Ritu, "Central and Peripheral Routes to Sustained Technology Usage" (2004). DIGIT 2004 Proceedings. 4. http://aisel.aisnet.org/digit2004/4

This material is brought to you by the Diffusion Interest Group In Information Technology at AIS Electronic Library (AISeL). It has been accepted for inclusion in DIGIT 2004 Proceedings by an authorized administrator of AIS Electronic Library (AISeL). For more information, please contact elibrary@aisnet.org. 


\title{
Central and Peripheral Routes to Sustained Technology Usage
}

\author{
Corey M. Angst \& Ritu Agarwal \\ University of Maryland \\ Robert H. Smith School of Business \\ Van Munching Hall \\ College Park, MD 20742-1815
}

December 2, 2004

Corey M. Angst, Ph.D. Candidate, cangst@rhsmith.umd.edu (ph 302-547-0487, fax 301-405-8655)

Ritu Agarwal, Ralph J. Tyser Professor of Information Systems, ragarwal@rhsmith.umd.edu

Address for both authors is as shown above 


\title{
Central and Peripheral Routes to Sustained Technology Usage
}

\begin{abstract}
In this paper we combine three theories of attitude and behavior change in an attempt to inform the under-studied concept of sustained technology usage over time. We address two broad research questions (1) what specific processes act to drive behavior change? and (2) does the route of persuasion accepted by the recipient affect the long-term behavior of the recipient, i.e. are the changes enduring? We use Kelman's (1958) processes of attitude change (i.e. compliance, identification, and internalization) as the three mechanisms through which the change can occur. We use the elaboration likelihood model (ELM) to provide a theoretical underpinning for understanding the cognitive elaboration that information recipients use when they are subject to persuasive messages. Finally, social learning theory helps us identify supervisors, work groups, and self as salient referents for behavioral modeling. We test our conceptual model using longitudinal data from a field study of users of a new customer relationship management system in a large financial services institution. Our results show that individuals are influenced to use technology by multiple processes including compliance, identification and internalization, and their usage over a span of one and a half years is either enduring or decreasing depending upon whether or not these information cues are processed through a central or peripheral route.
\end{abstract}




\section{Central and Peripheral Routes to Sustained Technology Usage}

\section{Introduction}

The importance of 'sustained' technology usage over time has been understudied in the information systems literature. Although the phenomenon of technology acceptance has been widely examined in an attempt to understand why individuals accept or reject technologies, much of the research in this genre has focused upon discrete decisions made at a specific point in time. Less emphasis has been placed on understanding the role of "others” and the messages and signals they send in changing an individual's technology use behaviors going forward and into the future. Rogers (1995) identifies “routinization” as the final stage in the diffusion of innovations, where the technology becomes an integral part of the work patterns of the adopter. In a similar vein, recent research points to the importance of studying continuance behavior in the context of information systems use (e.g. Bhattacherjee \& Premkumar, 2004). Bhattacharjee (2001) describes the acceptance-discontinuance anomaly as one where users initially accept a system but then fail to sustain their usage on a long-term basis. Our work likewise focuses on developing an understanding of technology use behavior over time, and its determinants. It departs from prior research in one important aspect: rather than examining only an individual's own beliefs and behavior and their temporal effects on continued use as has been done in extant research (e.g. Bhattacherjee \& Premkumar, 2004), we include a broader set of influences emanating from the context within which the individual is embedded.

We examine the process of behavior change over time and the receptiveness of the recipient to the persuasion method. Three theories of attitude and behavior change form the conceptual basis for our study: Bandura’s (1977) social learning theory, Kelman’s (1958) mechanisms of attitude change, and Petty and Cacioppo (1986b) elaboration likelihood model 
(ELM). We address two broad research questions (1) what specific processes act to drive behavior change? and (2) does the route of persuasion that is activated for the recipient affect the long-term behavior of the recipient, i.e. are the changes enduring? We use longitudinal data collected in three waves over a 30-month time period from over 300 users of a customer relationship management system to provide answers to these questions.

The remainder of this paper is structured as follows. We first present the theoretical background and develop the research hypotheses. This is followed by a description of the methodology, including the study context, the sample, construct operationalization, and analytical procedures. Next, results of the hypothesis tests are presented. Finally, the paper closes with a discussion of the results and directions for future research.

\section{Theoretical Background and Hypotheses}

Organizational members have numerous opportunities to interact with each other and transmit both verbal and non-verbal signals. Opportunities for interaction may arise out of physical proximity or simply because there are tasks that entail “working together.” The messages exchanged during such interactions can be interpreted by recipients in many different ways, and are frequently used to form attitudes and behaviors relative to a specific target. For example, when a new technology is introduced into a group, the behaviors and actions of others in the group - such as the amount of time they spend using the new technology - act as a cues for the recipient to fashion his or her usage. Kelman (1958) argues that the nature of the message greatly affects the type of change that is produced. He, and others, observe that some messages can produce "public conformity without private acceptance...[or]...public conformity coupled with private acceptance,” (Festinger, 1953; Kelman, 1953). In the following discussion 
we briefly describe Kelman's processes of attitude change, the ELM, and social learning theory as the foundation for our research hypotheses.

\section{Kelman's Processes of Attitude Change}

Kelman (1958) posits that social influence can occur at multiple levels. He also concludes that while the overt behavior of several individuals may be similar, the internal psychological processes that produce the behavior are likely to be quite different. From this basis, he describes three distinct processes of influence: compliance, identification, and internalization. The three forms of influence are similar in that each acts in a specific way to affect the behavior of a recipient. When the recipient receives this message, he or she can decide to give it any degree of elaboration or consideration varying from none to highly extensive. Where the processes of influence differ is in the underlying rationale for why they operate. Compliance generally occurs when the recipient wants to receive some sort of praise from another person, often a superior. The key to compliance is that the recipient adopts the behavior because of the extrinsic rewards she expects to reap and not the intrinsic belief that the behavior is warranted (Kelman, 1958).

The second form of influence, identification, often occurs in groups. When recipients desire to establish themselves as cohesive members of a group or team, they will accept influence most readily from those with whom they are most closely linked. With identification, the recipient typically believes in the behavior being exhibited by the group, but not because she feels strongly about the content, but primarily because the behavior nurtures the preferred relationship with her teammates (Kelman, 1958).

The final process of influence is labeled internalization. This is the only process in which the recipient is influenced based solely upon intrinsic rewards. These intrinsic rewards 
vary, but a common reason cited for accepting this type of influence is the belief that the new behaviors and actions align with one's current value system. The new beliefs are often integrated into the existing value system and therefore are typically more enduring than the prior two processes (Kelman, 1958).

\section{The Elaboration Likelihood Model and Social Learning Theory}

The ELM (Petty \& Cacioppo, 1986b) is one of two, dual-process theories of attitude formation and change arguing that persuasion can act via a central or peripheral route (Petty \& Cacioppo, 1981; Petty, Cacioppo, \& Schumann, 1983). The second theory, the HeuristicSystematic Model (Chaiken, 1980, 1987) is similar - and some would argue complementary (Eagly \& Chaiken, 1993 p. 346) - to the ELM, with one notable exception being that it lacks the empirical validation of the ELM. In both theories, attitudes are treated as being formed and modified as recipients get information about attitude objects (Eagly \& Chaiken, 1993 p. 257). Simply put, the ELM proposes that in different situations, message recipients will vary in the extent to which they cognitively elaborate on a particular message, due in part to the personal relevance of the message, personal responsibility, ability to cognitively assess the information, and motivation. These variations in elaboration likelihood will ultimately affect the cognitive schema of the recipient and determine the degree to which the recipient assimilates the information (Petty \& Cacioppo, 1981, 1986a, 1986b; Sussman \& Siegal, 2003).

According to Petty and Cacioppo (1981) there are two basic means to persuasion - a central route and a peripheral route. In the central route, attitude change is viewed as resulting from a careful consideration of the issues. Factors such as comprehension, learning, and retention of argument messages have been shown to influence the central route (e.g. Eagly, 1974; McGuire, 1968; Miller \& Campbell, 1959). Under the peripheral path, attitudes change because 
the attitude object has been associated with either positive or negative cues (Petty \& Cacioppo, 1981). The cues allow an individual to make decisions about her attitude without performing any extensive cognitive evaluation. Attitude changes do not occur because an individual has personally considered the pros and cons of the issue, but rather because the attitude issue or object is associated with positive or negative cues. The change can also occur because the recipient makes a simple inference about the merits of the advocated position based on various simple cues in the persuasion context (Petty et al., 1983). Attitude changes induced via the central route are viewed as being more enduring and predictive of behavior (Cialdini, Petty, \& Cacioppo, 1981 pp. 357-404; Petty \& Cacioppo, 1980) than those induced via the peripheral route. In the peripheral route, attitude changes are postulated to be relatively temporary and less predictive of behavior (Petty et al., 1983).

Finally, Bandura's (1977) social learning theory argues that one of the core mechanisms of learning is behavior modeling, where individuals learn vicariously through observation of others' behavior. Aiken (2002) notes that many attitudes may be imbibed "vicariously or imitatively" by observing the activities of other people. He further suggests that behavior modeling occurs not only in the case of verbal and motor skills, but also for attitudes, values, and beliefs.

Collectively, social learning theory, the ELM, and Kelman's theory of social influence illuminate the process of behavior change over time. Social learning theory informs us that behavior modeling can and does occur in work situations where opportunities for interaction exist. Relevant models include co-workers, supervisors, and self. Thus, what others around them do and believe influences individuals. Kelman's theory allows us categorize the influence of various models. Finally, ELM helps us predict the extent to which the influence of a 
particular model will be central or peripheral. Our interest is in examining behavioral changes related to technology use in contexts where individuals are nested within work groups in an organization and report to a supervisor. Such work arrangements are commonly prevalent in organizational settings, and therefore provide a useful milieu for our theorizing.

\section{Conceptual Model}

Figure 1 depicts our conceptualization of the effects of various role models and modes of persuasion and the processes through which the ELM acts.

**** Insert Figure 1 Here $* * * *$

Compliance. Kelman (1958) argues that behavior often results from a desire for external rewards. Social learning theory identifies those with authority as relevant role models. Thus, the attitudes and behaviors of supervisors will persuade individuals to use the technological innovation in the near term. To the extent the supervisor has the power of rewards and sanctions, it is the subordinate's desire for compliance that drives her behavior. Therefore we predict:

H1a: A manager's usage of a technological innovation will be positively related to her subordinates usage in the near term.

H1b: A manager's perceptions of the usefulness of a technological innovation will be positively related to her subordinate's usage in the near term.

$\underline{\text { Identification. }}$ Groups are a powerful social system in that they often induce conformity among members. As noted by Bandura (1977) in his explication of social learning theory, group members often serve as behavioral models. Because affiliation is important, the beliefs and behaviors of group members will persuade an individual to use a technological innovation in the near term simply because they want to "fit in." Therefore we predict: 
H2a: The average usage of a technological innovation by the individual's work group will be positively related to the individual's usage in the near term.

H2b: The average perceptions of the usefulness of a technological innovation of an individual's work group will be positively related to the individual's usage in the near term.

Internalization. The most potent form of "persuasion” is when the behavior aligns with the internal value system of the individual (Kelman, 1958). Here there is cognitive consistency (Festinger, 1953) among personal beliefs, attitudes, and behaviors. Such consistency is implicit in extant models of technology acceptance such as the TAM (Venkatesh \& Davis, 2000) that argue that prior beliefs and behaviors influence future behavior (Davis, 1989). Therefore we predict:

H3a: An individual's current usage of a technological innovation will be positively related to her usage in the near term.

H3b: An individual's perceived usefulness of a technological innovation will be positively related to her usage in the near term.

Central and Peripheral Routes: As observed above, we hypothesize that depending upon the route of persuasion (central or peripheral) that is active, the behavior enacted by the recipient may be enduring or short-lived. Many authors have suggested that central route persuasion will be more enduring than peripheral route (Cialdini et al., 1981 pp. 357-404; Petty \& Cacioppo, 1980) and Kelman (1958) notes that internalization is the most predictive and generates the most enduring behaviors relative to compliance or identification. Because internalization yields the most cognitive consistency and represents the highest form of motivation - intrinsic (Deci \& Ryan, 1985), we argue that internalization is a central route for behavior change. The individual is acting not because of external fiat or because of the desire to conform, but because the behavior is of value in and of itself. By contrast, it follows that compliance and identification 
will act through peripheral routes. While these pathways may produce transient behaviors when observed over the long-term, such behaviors are less likely to endure. Thus, we argue that the usage of a technology innovation will not change significantly over a span of one year in cases where central route persuasion is acting. On the other hand, usage will decrease when the source of persuasion comes through a peripheral route. Based on this reasoning, we predict the following:

Internalization versus Compliance

H4a: Individuals for whom near-term usage is more strongly determined by internalization than by compliance will not exhibit a significant change in usage in the long-term.

H4b: Individuals for whom near-term usage is more strongly determined by compliance than by internalization will exhibit a reduction in usage in the long-term.

H4c: Individuals for whom near-term usage is more strongly determined by internalization than by compliance, will exhibit a higher absolute usage of the technology in the near- and long-term than those individuals for whom compliance is greater than internalization.

\section{$\underline{\text { Internalization versus Identification }}$}

H5a: Individuals for whom near-term usage is more strongly determined by internalization than by identification will not exhibit a significant change in usage in the long-term.

H5b: Individuals for whom near-term usage is more strongly determined by identification than by internalization will exhibit a reduction in actual usage in the long-term.

H5c: Individuals for whom near-term usage is more strongly determined by internalization than by identification, will exhibit a higher absolute usage of the technology innovation in the short and long-term than those cases where identification is greater than internalization.

The empirical study conducted to test these hypotheses is described next. 


\section{Methodology}

\section{The Study Context and Sample}

The setting in which this field study was conducted is a banking institution (henceforth, "bank”) in the North-Eastern United States with branch offices located in several locations dispersed throughout the country. When we began the study in late October of 2002, the bank was just beginning to train employees in their "services” group to use a new customer relationship management (CRM) system. They had started a pilot program with a small group of employees about 6-months prior to our study.

Employees in the services group work in small teams headed by a manager, and typically consisting of one or more client liaisons, service providers such as trust or tax specialists, and several support staff. Each employee was required to attend a 3-day, 8-hour per day training session on the use of the CRM. Some employees attended 'refresher' courses later in the year, while still others were given extensive training in an attempt to identify them as localized experts.

The sample is drawn from all employees who work within teams in the services group at the bank. Of a total of 513 individuals targeted for the survey from a list provided by the executives at the bank, 344 usable surveys were completed for a response rate of $67.1 \%$. Tests for non-response bias between the first and second waves (after one reminder) of respondents indicated no significant differences in their perceptual and behavioral indicators. The format of the study required that we collect data from multiple levels of hierarchy within the services group. The identification of groups and supervisors or managers was accomplished through an organizational chart listing the positions of each of the 513 potential respondents in our sample. From the organizational chart, we were able to place each person in a workgroup and connect 
him or her with a manager. After closely scrutinizing the hierarchical structure, we were able to identify 38 managers and 43 groups within the relationship management division (demographic information is listed in Table 1). The average group size was just under 5.4 people, excluding the manager. For us to use an individual in the sample, we needed to have data from not only the individual respondent, but also her manager, and at least two members of her group. This yielded a final sample of 116 individuals, providing a working response rate of $33.7 \%$. **** Table 1 here $* * * * *$

Data for this study were collected in two primary phases and in the case of actual usage data, in monthly installments. Starting in May of 2002, the CRM system was rolled out to the bank employees in waves of 20-50 people at a time. By October 2002, the first phase of training and implementation was effectively completed. We began surveying the staff in waves coincident with the training waves in December of 2002 and completed the first phase of surveys in March of 2003. We confirmed that all of the respondents had approximately 6-months of system usage before we surveyed them. We began collecting monthly usage data in the form of CPU-minute logs and account activity when the system was rolled out in May 2002. For the second phase of the subjective portion of the data collection, we surveyed the same groups of people beginning in November of 2003. We had to work around the schedules of some of the groups but we were successful in surveying the vast majority of the subjects approximately one year after the initial survey and one and a half years after they were given the system. The second phase of data collection was completed in February of 2004. Objective data in the form of monthly usage was collected until October of 2004, giving us 29 months of objective usage data.

\section{Operationalization of Variables}


Influence, whether acting via compliance, identification, or internalization was operationalized in two ways - through actual usage and perceived usefulness of the CRM. When measuring compliance, we used the usage and usefulness of the individual's manager as the determinants of the individual's usage in later periods. Identification was measured in a similar way with the exception that we used an aggregate average of all group members' usage (excluding the focal individual) and usefulness as the predictors of the individual's lagged usage. Finally, we used the focal individual's actual usage and usefulness as predictors of her usage in later periods. The initial usage was collected in the last quarter of 2002 and was averaged to yield a monthly usage value.

For dependent variables, we strictly examined objective usage data collected by the bank's information system. As noted earlier, we collected data on a monthly basis but chose to analyze usage data from the $2^{\text {nd }}$ quarter of 2003 (short-term usage) and the $1^{\text {st }}$ quarter of 2004 (long-term usage) in an effort to be most inclusive of all users (recall that users were trained in waves so we wanted to include in the sample those respondents who were trained later). We also should note that usage data was collected up until October 2004 but the data were not made available to us in time for inclusion, hence we used the last complete quarter (Q104). As before, the data was averaged over a 3-month period to yield a monthly usage value. We did this in an effort to smooth peaks and valleys resulting from disruptions such as vacations and/or tax season.

\section{Results}

\section{Hypothesis Tests}


The reliability for the usefulness scale (Cronbach alpha) was 0.97, suggesting that the psychometric properties are acceptable. All other measures employed in this study were objective in nature. Hypotheses 1 through 3 were tested by regressing the dependent variable, use in the near term (USE03) on each of the independent variables: H1a, manager use (USE02_m); H1b, manager usefulness (PU02_m); H2a, group use (USE02_g); H2b, group usefulness (PU02_g); H3a, individual use (USE02_s); and H3b, individual usefulness (PU02_s). Results are shown in Table 2. In summary; manager, group, and individual usage predict usage in the near term, providing support for H1a, H2a, and H3a. With regard to usefulness, only individual usefulness predicted usage in the near term. Therefore, H3b was supported and H1b and H2b were not supported.

**** Table 2 here****

The next set of hypotheses test the supposition that behavior will be more enduring when the route of persuasion acting is central rather than peripheral. The three variations of hypothesis 4 compared the influence of internalization with that of compliance. We tested H4a and H4b using the following methodology. First, we calculated the standardized regression coefficients for each of the independent variables. Next, we subtracted the compliance coefficients from the respective internalization coefficients, i.e. Bcoef(USE02_s) - Bcoef(USE02_m). This yielded a net influence value that if positive, reflected an individual for whom internalization is a stronger predictor than compliance, i.e. use over time should not change significantly. If negative, compliance is a greater predictor than internalization i.e. use over time should decrease. We then split the sample into two groups; those with positive net influence (internalization-driven) and those with a negative influence (compliance-driven) and conducted paired t-tests between nearterm and long-term usage. These tests reveal that hypothesis $4 \mathrm{a}$ is supported, however $4 \mathrm{~b}$ is not 
supported (see Table 3). In fact, in H4b there was a statistically significant increase in usage over this period. Finally, in hypothesis 4c we asserted that internally motivated individuals would have a higher absolute usage in both the near- and long-term, than those motivated by compliance. We tested this hypothesis by using the same split criteria highlighted above but used a t-test comparing usage between internalization-driven versus compliance-driven individuals. Hypothesis 4c is supported in both the near- and long-term cases (see Table 4).

The last set of hypotheses tested the effect of internalization versus identification. We followed the same procedure outlined in Hypothesis 4 with the exception that we subtracted identification coefficients from internalization coefficients. Hypothesis 5a is supported, showing that individuals with a high internal motivation relative to identification have a non-significant change in usage over time. Hypotheses $5 b$ and $5 c$ were not supported (see Tables 5 and 6). In the case of H5b, the individual's usage actually increased significantly when the group effect was more powerful than the individual effect. In absolute usage terms, the group effect was also greater than the individual effect, leading us to reject hypothesis 5c. In summary, H4a, H4c, H5a were supported and H4b, H5b, and H5c were not supported.

**** Tables 3 through 6 here****

\section{Discussion and Conclusion}

Our objective in this paper was to understand "sustained" technology use, which we characterized as use that endures over time. Using theories of social learning, influence pathways, and persuasion routes we argued that the beliefs and behaviors of others would exhibit differential effects on enduring use. Data from a longitudinal study of a customer relationship management system were used to test the research hypothesis. 
Empirical support for our hypotheses is mixed. We find that near-term technology use is influenced by the behavior of managers, the group, and self. However, the beliefs of the manager and the group related to the usefulness of the technology are not related to the individual's near-term use. One explanation for this is that while the behavior of others around her in regard to system use is clearly observable by an individual, internal cognitions in the form of beliefs are less accessible. Therefore we failed to find the expected relationship between managers' and the group's usefulness beliefs and the individual's use.

In comparing the influence pathway of internalization versus compliance, contrary to expectations, our results show that those who are motivated initially by compliance rather than internalization not only endure in their technology use behavior, but their use increases over time. This suggests that the behavior of managers is a more potent influence in driving technology use than one’s own initial behavior. Although initially the finding may seem counterintuitive, the explanation possibly resides in what Bandura (1977) refers to as the competence of the role model. To the extent that individuals believe that their managers are more competent than themselves and aspire to achieve the same status, they are likely to model their behaviors on the manager, rather than on their own. This raises an interesting question for future work: does the competence of the manager moderate the effects of compliance-based vs. internalization-based influence? Or alternatively, does an individual's self-efficacy moderate the effects of different role models?

Likewise, in comparing effects of internalization versus identification, we find that whereas the former leads to behaviors that persist, the latter yields an increase in technology use behavior, suggesting that group influence is indeed persuasive and compelling. Thus, although our initial assertion that internalization results in changes via a central route while identification 
operates through a peripheral route is technically supported, the findings point to the need for a more nuanced approach to understanding behavior change. Rather than characterizing behavior simply as persistent or temporary, we need to consider the direction of the change in peripheral routes. This again raises intriguing issues for future work: it is possible to isolate three distinct behaviors related to technology use: enduring (no change over time), positively reinforced (increasing), and declining. Changes via a peripheral route are not necessarily undesirable if they result in positive reinforcement. Future research could be focused on understanding in greater depth how the influence pathways and role models affect the three types of long-term behavioral change.

In addition to the directions for future research identified above, this study highlights the need for additional conceptualization to more fully understand the determinants of sustained technology use. We drew upon theories of attitude and behavior change, but there are other theoretical perspectives that could be informative as well - such as those related to the different forms of motivation (Deci \& Ryan, 1985). For practice, the clear recommendation that emerges from our results is that the behavior of colleagues influences individuals over and above their own behaviors. Managers therefore need to be sensitive to virtuous cycles of reinforcement versus vicious cycles of decline. Early extensive use by colleagues and supervisors will set a virtuous cycle in motion, while low initial use will eventually result in widespread “disuse”.

In conclusion, this paper sheds further light on an understudied area in technology adoption research - the sustained use of a technology over time. From a theoretical perspective, its contribution is in the synthesis of different theories of behavior change into one unified model that helps isolate the causal pathways and mechanisms through which change occurs. Empirically, our longitudinal field data gives us a unique opportunity to provide a rigorous test 
of the proposed relationships. Particularly, the fact that our data allows us to examine influences at multiple levels of analysis is a strength of the study. Clearly, an understanding of persistent behavior is of interest not only to the research community, but also to practitioners for whom value is perhaps best appropriated when technology use is enduring. 


\section{References}

Aiken, L. A. (2002). Attitudes and Related Psychological Constructs: Theories, Assessment, and Research. Thousand Oaks, CA: Sage.

Bandura, A. (1977). Social Learning Theory. Englewood Cliffs, NJ: Prentice Hall.

Bhattacherjee, A. (2001). Understanding information systems continuance: An expectationconfirmation model. MIS Quarterly, 25(3), 351-370.

Bhattacherjee, A., \& Premkumar, G. (2004). Understanding Changes in Belief and Attitude Toward Information Technology Usage: A theoretical model and longitudinal test. MIS Quarterly, 28(2), 229-254.

Chaiken, S. (1980). Heuristic versus systematic information processing and the use of source versus message cues in persuasion. Journal of Personality and Social Psychology, 39(5), $752-766$.

Chaiken, S. (1987). The Heuristic Model of Persuasion. In C. P. Herman (Ed.), Social Influence: The Ontario Symposium. Hillsdale, NJ: Erlbaum.

Cialdini, R. B., Petty, R. E., \& Cacioppo, J. T. (1981). Attitude and Attitude Change. In L. Porter (Ed.), Annual Review of Psychology (Vol. 32). Palo Alto, California: Annual Reviews.

Davis, F. D. (1989). Perceived usefulness, perceived ease of use, and user acceptance of information technology. MIS Quarterly, 13, 319-339.

Deci, E. L., \& Ryan, R. M. (1985). Intrinsic motivation and self-determination in human behavior. New York: Plenum.

Eagly, A. H. (1974). Comprehensibility of Persuasive Arguments as a Determinant of Opinion Change. Journal of Personality and Social Psychology, 29, 758-773.

Eagly, A. H., \& Chaiken, S. (1993). The Psychology of Attitudes. Orlando, FL: Harcourt Brace Javanovich, Inc.

Festinger, L. (1953). An Analysis of Compliant Behavior. In M. O. Wilson (Ed.), Group Relations at the Crossroads. New York: Harper \& Bros.

Kelman, H. C. (1953). Attitude Change as a Function of Response Restrictions. Human Relations, VI, 185-214.

Kelman, H. C. (1958). Compliance, Identification, and Internalization Three Processes of Attitude Change. Journal of Conflict Resolution, 2(1), 51-60.

McGuire, W. J. (1968). Personality and Attitude Change: An information processing theory. In T. M. Ostrom (Ed.), Psychological Foundations of Attitudes. New York: Academic Press.

Miller, N., \& Campbell, D. T. (1959). Recency and Primacy in Persuasion as a Function of the Timing of Speeches and Measurements. Journal of Abnormal and Social Psychology, 59, $1-9$.

Petty, R. E., \& Cacioppo, J. T. (1980). Effects of Issue Invovlement on Attitudes in an Advertising Context. In M. E. Goldbertg (Ed.), Proceedings of the Division 23 Program (pp. 75-79). Montreal, Canada: American Psychological Association.

Petty, R. E., \& Cacioppo, J. T. (1981). Attitudes and Persuasion: Classic and contemporary approaches. Dubuque, Iowa: Wm. C. Brown.

Petty, R. E., \& Cacioppo, J. T. (1986a). Communication and Persuasion: Central and Peripheral Routes to Attitude Change. New York: Springer-Verlag. 
Petty, R. E., \& Cacioppo, J. T. (1986b). The Elaboration Likelihood Model of Persuasion. In L. Berkowitz (Ed.), Advances in Experimental Social Psychology (Vol. 19). San Diego, CA: Academic Press.

Petty, R. E., Cacioppo, J. T., \& Schumann, D. (1983). Central and Peripheral Routes to Advertising Effectiveness: The Moderating Role of Involvement. Journal of Consumer Research, 10(2), 135-146.

Rogers, E. M. (1995). Diffusion of Innovations (4th ed.). New York: The Free Press.

Sussman, S. W., \& Siegal, W. S. (2003). Informational Influence in Organizations:An Integrated Approach to Knowledge Adoption. Information Systems Research, 14(1), 47-65.

Venkatesh, V., \& Davis, F. D. (2000). A Theoretical Extension of the Technology Acceptance Model for Longitudinal Field Studies. Management Science, 46(2), 186-204. 
Figure 1. Conceptual Model

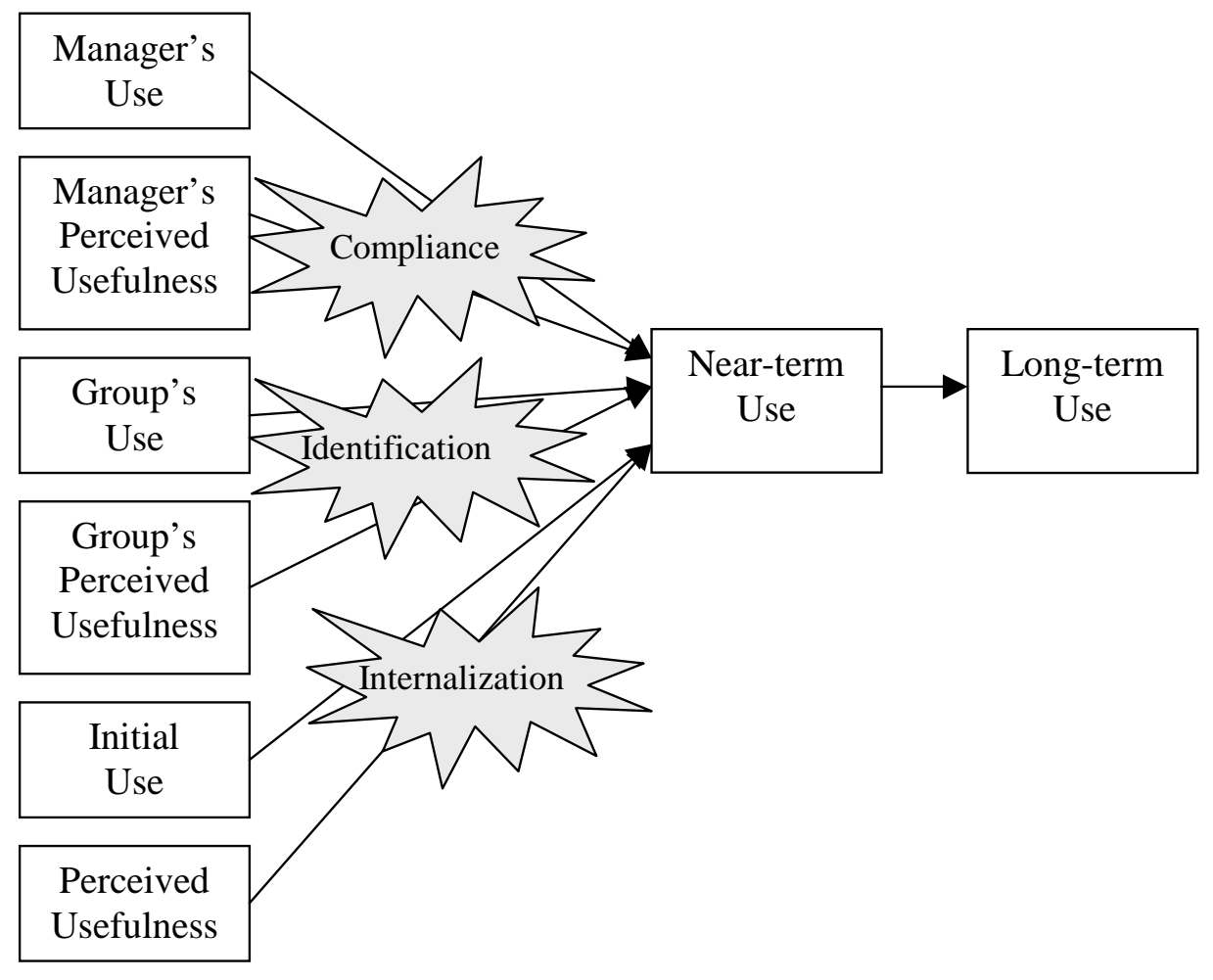

Table 1. Descriptive Statistics

\begin{tabular}{|c|c|c|}
\hline Description & Subset & Value \\
\hline \hline Demographics & Age & $31-40 \mathrm{yrs}$ \\
& Education & At least BA \\
& PC Experience & $15.5 \mathrm{yrs}$ \\
& Years with the bank & $9.3 \mathrm{yrs}$ \\
& Total work years & $20.8 \mathrm{yrs}$ \\
\hline
\end{tabular}

Table 2. Regression Coefficients, Hypotheses Testing H1-H3

\begin{tabular}{|lccccc|}
\hline & $\begin{array}{c}\text { Unstd. } \\
\text { Coefficients }\end{array}$ & \multicolumn{5}{c|}{$\begin{array}{c}\text { Standardized } \\
\text { Coefficients }\end{array}$} \\
\hline & B & Std. Error & Beta & t-statistic & p-value \\
\hline (Constant) & -6.380 & 6.855 & & -0.931 & 0.354 \\
H1a: USE02_m & 0.027 & 0.008 & 0.276 & 3.315 & $0.001^{\star \star \star}$ \\
H1b: PU02_m & -0.001 & 0.790 & 0.000 & -0.002 & 0.999 \\
H2a: USE02_g & 2.019 & 0.509 & 0.344 & 3.965 & $0.000^{\star \star \star}$ \\
H2b: PU02_g & 0.817 & 1.678 & 0.046 & 0.487 & 0.627 \\
H3a: USE02_s & 0.041 & 0.013 & 0.258 & 3.287 & $0.001^{\star \star \star}$ \\
H3b: PU02_s & 1.861 & 0.725 & 0.207 & 2.567 & $0.012^{\star}$ \\
\hline
\end{tabular}

Dependent Variable: Near-Term Use (USE03)

*** $\mathrm{p}<.001,{ }^{* *} \mathrm{p}<.01,{ }^{*} \mathrm{p}<.05$ 
Table 3. T-Tests, Hypothesis 4a,b Testing

\begin{tabular}{|lccccc|}
\hline Source of Persuasion & Measures & Mean & N & Std. Dev & 2-tailed sig. \\
\hline H4a: Internalization > Compliance & USE03 & 20076.5 & 68 & 10712.08 & 0.632 \\
& USE04 & 20588.6 & 68 & 12217.24 & \\
\hline H4b: Compliance $>$ Internalization & USE03 & 7184.8 & 175 & 10467.7 & $.002^{\star \star}$ \\
& USE04 & 8908.5 & 175 & 11686.9 & \\
\hline
\end{tabular}

Table 4. T-Tests, Hypothesis 4c Testing

\begin{tabular}{|rccccc|}
\hline Source of Persuasion & Measures & Mean & $\mathrm{N}$ & Std. Dev & 2-tailed sig. \\
\hline H4C: Internalization > Compliance & USE03 & 20076.5 & 68 & 10467.7 & $.000^{\star \star \star}$ \\
Compliance $>$ Internalization & USE03 & 7184.8 & 175 & 12217.24 & \\
\hline H4C: Internalization > Compliance & USE04 & 20588.6 & 68 & 10712.08 & $.000^{\star \star}$ \\
Compliance $>$ Internalization & USE04 & 8908.5 & 175 & 11686.9 & \\
\hline
\end{tabular}

Table 5. T-Tests, Hypothesis 5a,b Testing

\begin{tabular}{|lccccc|}
\hline Source of Persuasion & Measures & Mean & $\mathrm{N}$ & Std. Dev & 2-tailed sig. \\
\hline H5a: Internalization > Identification & USE03 & 8776.3 & 126 & 11091.7 & 0.652 \\
& USE04 & 8503.7 & 126 & 11475.3 & \\
\hline H5b: Identification > Internalization & USE03 & 11887.7 & 131 & 12357.5 & $.000^{\star \star \star ~}$ \\
& USE04 & 14784.8 & 131 & 13363.2 & \\
\hline
\end{tabular}

Table 6. T-Tests, Hypothesis 5c Testing

\begin{tabular}{|lccccc|}
\hline Source of Persuasion & Measures & Mean & $\mathrm{N}$ & Std. Dev & 2-tailed sig. \\
\hline H5c: Internalization $>$ Identification & USE03 & 8776.3 & 126 & 11091.7 & $.000^{\star \star \star}$ \\
Identification > Internalization & USE03 & 11887.7 & 131 & 12357.5 & \\
\hline H5c: Internalization > Identification & USE04 & 8503.7 & 126 & 11475.3 & $.000^{\star \star}$ \\
Identification > Internalization & USE04 & 14784.8 & 131 & 13363.2 & \\
\hline
\end{tabular}


$\underline{\text { Scales }}$

PU

Using the [CRM] system in my job will enable me to accomplish tasks more quickly (PU1) Using the [CRM] system helps me to better serve my clients (PU2)

Using the [CRM] system will improve my job performance (PU3)

Using the [CRM] system in my job will increase my productivity (PU4)

Using the [CRM] system will enhance my effectiveness on the job (PU5)

Using the [CRM] system will make it easier to do my job (PU6)

I will find the [CRM] system useful in my job (PU7) 